\title{
Introduction to the Use of Zhuang Embroidery Element in Fashion Design
}

\author{
Shuxian Huang \\ Jiangxi institute of fashion technology Jiangxi Nanchang
}

362112768@qq.com

Keywords: Costume design zhuang; Nationality embroidery; National element; embroidery

\begin{abstract}
In the contemporary clothing design, the embroidery elements of the Zhuang nationality are widely used, and the embroidery elements of the Zhuang nationality are colorful and colorful, which can add a touch of Zhuang culture to the clothing. The patterns and colors of the embroidery elements of the Zhuang ethnic group reflect the national characteristics, not only the embroidery is fresh and elegant, but also the needle is very rich, which embodies the different cultural customs and clothing characteristics of the different embroidery branches of the Zhuang nationality in Guangxi, and embodies the rich and colorful culture. In the branches of the Zhuang embroidery, this article focuses on the Zhuang people in Guangxi Zhuang clothing, Guangxi Zhuang nationality clothing is the living fossil. The embroidery elements in the clothing design to wear black clothing as the standard of beauty, ethnic elements of embroidery patterns are widely used in which, has always been to the United States to enjoy.

Zhuang embroidery workmanship is very fine, often words: "Zhuang embroidery needle see foundation, the line of the effect." Zhuang women are better at weaving and embroidery, there are two kinds of cloth, which are Strong cloth and Zhuang brocade, in which many new embroidery patterns, add a lot of color for the Zhuang costumes. Zhuang embroidery is very particular about the overall layout, generally embroidered as the main body, and to intensive embroidery for its main tone to a large area of embroidered features. Therefore, the majority of embroidery Zhuang embroidery is very stretch the atmosphere and dazzling. At the same time, because the Zhuang embroidery needs to spend a lot of energy and time, so the embroidery is very durable.
\end{abstract}

\section{A Study on the Embroidery Elements of Black Dress Zhuang Costume Jewelry}

The Influence of the Current Zhuang Embroidery on Clothing. In Guangxi, Zhuang embroidery application is very extensive, folk embroidery activities are also colorful. With the national culture has been valued, many Zhuang women wearing a variety of embroidery clothing, wearing all kinds of Zhuang embroidery headdress, looks gorgeously dressed and national characteristics panoramic view. At present, Zhuang ethnic costumes are still relatively common in the minority areas of Guangxi, Especially in the rural areas where the Zhuang people live, and the remote mountain areas of the Zhuang nationality The clothing of the residents still retains the characteristics of their ethnic groups. For example: the man with a green cloth breasted shirt-based, or accompanied by Buppa head; and women's dress pattern more, vary, different characteristics. Zhuang's women's upper body is usually wearing no collar Xie Jin embroidered piping shirt (some are without collar Xie Jin's black T-shirt), the lower body with embroidered piping wide-leg pants (or black wide-leg pants) or green batik Skirt-based, waist accessories generally embroidered Wai-based, as well as embroidered shoes is one of the major characteristics of the Zhuang. Zhuang women's head, Zhuang women head wrapped in All kinds of towels, like to use silver jewelry for decoration, there are some places on the head package into the shape of the black Pa.

Guangxi Zhuang Autonomous Region is the gathering of the Zhuang ethnic province, and the black Zhuang Zhuang is a branch, they live in groups, the distribution is relatively wide, simple folk customs, is the traditional "patron" typical life self-sufficiency. The black Zhuang Zhuang Zhuang is also the most distinctive clothing, in general, followed the overall characteristics of the Guangxi Zhuang clothing design, style, more relaxed and comfortable, mainly taking into account the 
convenience of labor. Black clothing Zhuang a series of clothing is mainly selected soft and density of large yarn fabric, this material can make clothing more comfortable to wear, but also more drape. Black zhuang series of clothing on the choice of fabric color, mainly navy and dark blue, set off the black zhuang "black" as the tradition of beauty.

\section{Black Clothing Zhuang Clothing Research}

Black clothing Zhuang has a long history, embodies the traditional black clothing Zhuang traditional culture, rich cultural heritage, distinctive clothing characteristics. Black clothing Zhuang is rare to "black" as beauty, Black as the symbol of the national costumes; clothing mainly reflects the simple, generous and practical concept of style. Black clothes Zhuang costume is divided into three parts: the first suit, clothing, and clothing.

First of all, from the head of clothing, black women Zhuang basically everyone will have a head of black cloth, that is, headgear. Women in black women are generally easy to wear Zhuangtou long hair. As a headdress of the black cloth worn on the head like a hat, the headwear looks simple, but its use, production methods, design and so have strict requirements. For example: married women and unmarried women's headdress is not the same, and everyone can according to their aesthetic to the necessary costumes, it can be said, until now, the black clothing still retains the traditional Zhuang Touyi culture, in the Black Zhuang Zhuang village, the headwear culture can be seen everywhere. The women of the black Zhuang women used to hair into a bun and rolled in the head, and through a width of two to three inches of white turban to wrap up the hair, so the hair can be fixed in the head, easy to put and use silver hairpin; And then on the outside with black Zhuang characteristics of black or dark blue cloth folded in the head. Black and white Zhuanglou can play a fixed role, with the outside on the brown t-shirt, and then use the red line sewing, but the red line is very thin and sewn in the Folding out far to see do not come out, fully embodies the black Zhuang clothing simple and elegant, simple temperament. In addition, because the black cloth is the first step on the local sewing, the texture is relatively hard and difficult to produce deformation, which is conducive to maintaining the beauty of headwear.

Secondly, in the clothing, mainly including the shirt and pants. Black clothing Zhuang body clothing are very fine workmanship, mainly composed of pieces, namely collar, skirt, back, sleeves, etc. are cut, the reason for doing so is to make clothing look more layered And beautiful.

Finally, in the foot clothing mainly reflected in the work of the shoes. General Black Zhuang Zhuang girls to a certain grade must be learned from the mother after the shoe craft, work more complex, and the design to a variety of hand-embroidered methods. Shoes, the main color is black, accompanied by bright color of secondary colors, black clothing for the traditional added vitality.

\section{Second, Black Clothing Zhuang Embroidery in the Design of the Application}

Bronze Drum Culture on the Impact of Modern Black Clothing Zhuang. The application of the embroidery elements in the black clothing of the Zhuang nationality has long been influenced by the bronze drum culture. Bronze drums as a percussion instrument, has long been used by the black Zhuang people. What began in the Pearl River Basin Chinese Pu started making drums, but because the percussion drums, can produce a vigorous and full of momentum is very encouraging voice, so, Tonggu production technology is widely disseminated, and in Guangxi, Guangdong, Sichuan To develop. With the development of the times, many parts of the drum culture has disappeared, China currently retains the most is the bronze drum percussion instruments, while the black Zhuang also retains the traditional bronze drum production process for two thousand years of drums Culture left a "living fossil". At the same time, the bronze drum culture has been profoundly affecting the local people's aesthetic, black clothing Zhuang in the embroidery patterns, materials, color and so on to express the local people to overcome the confidence of the natural creation of culture, a lot of black Zhuang ethnic costumes are embroidered bronze Pattern, to show the national culture and the cultural connotation of the steady manner. 


\section{Black Clothing Zhuang Embroidery in Modern Clothing Design Applications}

With the continuous development of the times, clothing design back to nature, return to the concept of maturity, the current design of embroidery in the use of embroidery is very extensive, especially the black Zhuang embroidery, embroidery process, pattern, color choice, are The full display of the national characteristics and designers of the personality, ideas, designers often get the love, practice, a lot of black Zhuang embroidery is often applied to modern clothing, effectively increasing the characteristics of modern clothing, especially in the Advanced custom clothing design will often see the embroidery elements. The embroidery patterns of the black Zhuang people have bright colors and bright colors, and they have a very strong three-dimensional sense. In the process of modern garment production, the use of embroidery has become the mainstream of the current fashion design. In the modern clothing in the use of Zhuang embroidery elements, especially in black and black Zhuang embroidery, choose some embroidered with auspicious meaning of the pattern, not only to highlight the characteristics of clothing to meet the individual needs of consumers, At the same time, through the traditional culture to promote,Can increase the cultural connotation of clothing, making clothing more colorful. In addition, the current embroidery in the use of traditional design, stitching, patterns, but also joined the modern elements, into the modern technology, effectively black embroidery Zhuang embroidery method and other embroidery methods, patterns and colors On the full integration, the effective realization of the national culture of innovation and dissemination.

\section{Black Clothing Zhuang Embroidery in the Application of Men's Clothing}

In practice, black clothing Zhuang embroidery in the application of men's clothing is more extensive. Men's clothing applications, can be integrated into the Zhuang clothing style and clothing culture to change, such as: the use of black Zhuang ethnic customs or black clothing Zhuang ethnic culture design clothing, because the clothing of the black Zhuang Zhuang more elegant, simple, Masculine and so on, men's clothing can be embroidered on the black Zhuang bronze drum design, fully embodies the tradition of the ancient minority of the wind. At the same time, with the overall color with clothing, highlighting the masculine side of the man. In the choice of fabric, the use of more drape strong fabric, fully embodies the male in the simple recklessness in the walk, you can also use a small amount of modern design to strengthen the black clothing Zhuang culture, full use of three-dimensional embroidery patterns and colors, for the men's series of clothing to add color and highlights. However, In modern clothing, many of the main design is done by machine embroidery, the embroidery fully integrated into the modern garment design.

Fourth, the conclusion

Zhuang wind design in modern clothing design is widely used, especially in Guangxi Zhuang traditional embroidery patterns, etc., in the modern national wind costume design has been widely used. However, for the black ethnic Zhuang ethnic minorities such as the costume of embroidery elements, in modern clothing design used in the still less, Hope that the protection on the basis of the zhuang minority costume culture,Zhuang embroidery charm can be in the current Clothing design can make a breakthrough, so that the charm of black clothing Zhuang Zhuang can be durable, so that more people like the Zhuang embroidery and clothing.

\section{Acknowledgements}

The educational reform in Jiangxi Province in 2015 "task driven teaching method in the" CorelDRAW "clothing computer curriculum research and application" stage results, project number: JXJG15-26-5

\section{References}

[1] YC Gao. Study on the Dong embroidery culture and visual language analysis [J]. Journal of Popular Literature 2015 (22) 
[2] CY Huang Cultural symbol of Chinese traditional folk embroidery patterns [J] .Shandong Textile Economics. 2011 (01)

[3] Y Ma. Hand-embroidered fashion research and application [D]. Beijing Institute of Clothing 2012

[4] RZ Ma Guoyun.Clothing Design: National Costume Elements and Application [M]. Beijing: China TextilePress, 2015.1.

[5] Y Zhou Chinese minority clothing arts and crafts [M]. Beijing: China Textile Publishing House, 2014.2

[6] JY Xu ,HW Zuo .Study on the Study of Chinese Minority Embroidery Pattern Culture [J] .Art Education Research 2016 (19)

[7] LR Chen Hangzhou embroidery on the protection of heritage and development [J]. Hangzhou (weekly) .2016 (19)

[8] SZ Tao Modern embroidery jewelry pattern design [J]. Modern Decoration (Theory). 2016 (10)

[9] XY Tang Application of Embroidery in Dress Design [J] .Art Tasting. 2016 (12)

[10]G LEI, NN ZHANG .Traditional and modern - On the expression of traditional and modern embroidery [J] .Art of Fine Arts. 2008 (12) 